\title{
Utilizing Supercapacitors for Resiliency Enhancements and Adaptive Microgrid Protection against Communication Failures
}

Hany F. Habib, A. A. S. Mohamed, Mohamad El Hariri and Osama A. Mohammed

Corresponding Author:

Osama Mohammed

Energy Systems Research Laboratory, Department of Electrical and Computer Engineering

Florida International University, Miami, Florida, USA 33174

E-mail: mohammed@fiu.edu

Phone: +1 (305) 348-3040, Fax: +1 (305) 348-3707

Abstract-Islanded microgrids do not have sufficient resources to contribute enough fault current to legacy protection devices to continue operation. Therefore, when a fault happens in an islanded microgrid, relays with high fault current setting will fail to detect and clear the fault. Contemporary adaptive protection schemes rely on communication technologies to adjust the relay settings to adapt to the microgrids' modes of operation; grid-connected or islanded. However, the risk of communication link failures and cyber security threats such as denial-of-service represent major challenges in implementing a reliable adaptive protection scheme. In order to address this issue, this paper proposes an adaptive protection scheme which utilize super capacitive energy storage to enhance resiliency against communication outages. This paper also introduces an autonomous control algorithm developed for the super-capacitor's AC/DC converter. The proposed control is capable of deciding upon charging, discharging of the super-capacitor, and whether or not to feed fault currents in the AC side, based on direct voltage and frequency measurements from its connection point with the microgrid. This eliminates the need for a control command to be sent from the point of common coupling of the microgrid with main grid to adjust the controller's mode of operation and thus reducing the risk of controller failure due to cyberattacks or other communication issues. Additionally, the paper proposes a solution to avoid installing a larger super-capacitor by temporarily disconnecting the uncritical pulsed load during the fault instant. The proposed protection scheme was investigated through simulation for various fault types and showed successful results using the proposed scheme in eliminating the aforementioned faults when the communication were available or attacked.

Keywords: Adaptive protection, cyber-attacks, microgrid, supercapacitor, pulsed loads. 


\section{INTRODUCTION}

Future power network will feature many microgrids especially at the electric distribution level and delivering clean renewable energy close to the end user [1]. Along with these benefits, microgrids introduce many challenges for power system operations and protection strategies. Legacy protection schemes were designed for passive distribution networks are not suitable for use in microgrids [2]. This is because, besides feeding local load, a microgrid is also expected to export power to the main grid and other microgrids and thus requiring a bi-directional power flow. The bi-directional power flow affects the amplitude of the fault currents [3]. Also, the short circuit fault current capacity of the system may get affected by any change in the microgrid configuration either due to the integration or the disconnection of DGs in the existing grid. In grid connected mode, the main grid will provide enough high fault current to activate fault protection devices (typically 3-6 times normal rated current is required). However, an islanded microgrid is dominated by power electronic interfaces and these inverters will have a maximum current rating of perhaps 1.5-2 times normal rated current [4]. At the very least, a system that is designed to protect a microgrid should take the following into account; (a) bidirectional power flow in feeders; (b) reduced fault levels in islanded operation [5]-[7]. In order to protect AC microgrids in both grid-connected and islanded modes of operation, an adaptive protection scheme is required [8]. The adaptive protection system consists of a smart control unit that monitors the grid parameters, a smart fault diagnostic system to detect the fault, fault type, and the faulted zone and a smart relaying system which protects the system against faults. A major issue related to the smooth operation of adaptive microgrid protection scheme in a smart grid scenario is the prior knowledge of every state of the grid and the online monitoring and calculation of the short circuit fault current level for every small change in the grid configuration [9]. This requires application of a communication system with a backup and fast data acquisition system between generators, the protective devices and loads etc., so that shifting between high and low relay settings can be done automatically [10]. In [11]-[13], central protection approaches are proposed to calculate the fault current of the distributed energy resources (DERs). This system can be used to monitor a microgrid over communication lines and react to dynamic changes of the system. Authors in [14] calculate both the system's and the microgrid's impedances by measuring the voltage and current fault in a real-time manner, the protection device will send a trip signal to circuit breakers according to the value of impedance that changes simultaneously with the system topology. The authors in [15] change the time-current characteristics for short circuit and overload conditions by observing the difference in voltage drops during these two events respectively. Most of the proposed adaptive protection methods are completely dependent on exchange or transfer of data/information in the shape of measured system parameters and direction and 
interlocking signals between different protection devices via some kind of communication link. The existing adaptive protection schemes are condition specific and innovated as per the developments happened in the grid configuration from time to time [16]. The authors in [17] added supercapacitor with DC-DC converter to each DERs with the same rated power that will add to the cost of the protection system especially that the supercapacitors are not used during normal operation. They are used only to feed the fault. [18] Presents a technique to protect the microgrid based on voltage measurement of the fault detection modules to detect the fault, but this may not be accurate to determine the faulted part in the system and may need time. This will have direct effects on the selective protection of the microgrid.. Communication failure is a critical issue which has been widely presented in the engineering literature [19]. The operation of the relay depends on the drop of the voltage during the fault that may cause to disconnect a lot of loads in the system. On the other hand, with using supercapacitor bank in the system, when the communication is not available, the supercapacitor can inject current immediately and help the relay that should work to isolate the fault from the system without disconnecting large parts in the system. [20] Provides a review about the different techniques that can be used to protect the microgrid. It relates to our paper by stating that the communication is necessary to protect the system but it cannot provide a solution to cyber-attacks.

It is therefore evident from the recent literature that incorporation of communication technologies into microgrids has become inevitable to provide contemporary adaptive protection schemes. However, the complex interdependencies between the cyber and the physical components of such systems increase the difficulty of devising control algorithms for them. The challenge is in the fact that in an extremely interconnected cyber-physical system, such as adaptive protection in microgrids, minor unconventionalities in the cyber domain can have catastrophic impacts in the physical domain [21]. In order to address the subject matter, extensive efforts have been placed to devise data communication standards for power transmission. Realizing its criticality in power transmission, communication requirements for protection algorithms are looked at in extensive details in international standards such as IEC 61850. IEC 61850 standard was developed by the International Electro-technical Commission (IEC) Technical Committee Number 57 Working Group 10 and IEEE for Ethernet (IEEE 802.3)-based communication in electrical substations [22] and is currently being extended for use tele-protection (IEC 61850-90-1). IEC 61850 is also mentioned in recent literature for microgrid applications [6]. Standards addressing protection applications realizes their criticality and thus poses stringent restrictions on messages that communicate fault-related signals such as the $4 \mathrm{~ms}$ time limitation imposed on SMV and GOOSE messages by IEC 61850. Therefore, designing control algorithms for protection system is a delicate and complex procedure. This complexity is further leveraged when dealing with adaptive protection algorithm design in which the 
collaboration between multiple agents, namely Intelligent Electronic Devices (IEDs), for detecting and isolating faults is time-critical.

Here again, the robustness and availability of the communication infrastructure is an important prerequisite for the success of contemporary adaptive protection algorithms. Therefore, communication failure in such applications is a high priced risk with serious consequences. Therefore, the goal of a resilient adaptive protection algorithm is to ride through communication failures without serious damage to hardware assets (transmission lines in this case), financial, or productivity costs. Considering the above factors, in this work, an adaptive protection scheme for AC microgrids, which is capable of surviving communication failures by the aid of energy storage systems, is proposed. The microgrid under study comprises an AC side feeding various resistive loads with different ratings and a DC side having a supercapacitor supplying a pulse. The power flow between the two sides is achieved by using three-phase AC/DC voltage source converter (VSC). A fuel cell is also used as a DC source in the system studied to assist the AC generators in supplying their loads. The microgrid operates in a grid connected and in an islanded mode of operation and thus the proposed protection scheme adjusts the protection relays' settings in order to detect and isolate faults in both modes of operation. That is, as long as the microgrid is connected to the main grid, the relays' settings are adjusted to their High Settings since the main grid will have the main contribution for the fault current in order for the relays to detect it. However, in the islanded mode, there won't be enough resources to contribute to the fault current and thus the relays' settings must be reduced to the Lower Settings. The shift between the two settings comes from a command signal issued by the point of common coupling (PCC) to all relays according to the current mode of operation. In the event of communication failure during the islanded operation, relays' settings will not be adjusted to the lower setting and thus faults will not be detected. The proposed solution takes benefit from the installed supercapacitor in the system with the bidirectional VSC to contribute for the fault current and raise this current value to level which is sensed by the High relay settings. The proposed solution does not incur additional costs to the system studied as the supercapacitor is already used to feed the pulse load. It is also worth noting here that the design of the proposed controller for the supercapacitor's AC/DC converter is capable of operating when the microgrid is in both grid-connected and islanded mode. Utilizing a single mode of operation for the converter will eliminate the reliance on communication control command signals to shift the controller between different modes. The system, as will be detailed later in the paper, is also designed to maintain stable voltage and frequency levels even during extreme cases such as the occurrence of a fault during a peak pulse load period.

The rest of the paper is organized as follows: Section II presents a description of the system under study. Section III describes the protection algorithm and the different settings of the protection devices according 
the different microgrid modes of operation. Section IV explains the control of the supercapacitor-based microgrid and its importance in contributing to the fault current in cases where communication is lost. Section V presents an analyses of the simulation results. Finally, Section VI concludes the work.

\section{HYBRID DC/AC MICROGRID DESCRIPTION}

Fig.1 shows the topology of the hybrid AC/DC microgrid under study with grid connection capabilities. The system contains three types of sources: two distributed generators in the AC part of the microgrid, a super capacitor bank to supply a DC pulse load, and a fuel cell. A three phase transformer is implemented to feed the AC microgrid with the required rated voltage. The system has a filter located between the transformer and the AC microgrid to filter out the harmonics of the AC grid. Another AC filter is added between the AC and DC parts of the microgrid to improve the performance of the bidirectional and unidirectional converters and reduce the harmonics of the $\mathrm{AC}$ microgrid as well. The bidirectional converter that is connected between the supercapacitor and the $\mathrm{AC}$ side is used for charging the supercapacitor in the normal operation. During islanded operation, and when there is a communication failure, the bidirectional converter allows the supercapacitor to contribute to the fault current during the occurrence of a fault in AC side. The unidirectional converter is present to allow DC sources to support AC sources in feeding various loads in the microgrid. A relay and a circuit breaker is connected to each end of all transmission lines. CB11 and CB12 are connected at the terminals of the DC sources and provide the ability to connect and disconnect these sources. F1 is applied to the system in order to isolate the microgrid from the grid, then another fault, F2, is applied on the islanded microgrid to investigate its performance with and without communication. The super capacitor in Fig. 1, which is connected through a bidirectional VSC to the AC microgrid, is of paramount importance for the role it plays in contributing to the fault current when the communication medium fails as will be explained in details later in this paper. The super capacitor is of $2.9 \mathrm{~F}$ capacitance and it delivers high instantaneous power to the pulse load during the normal operation. The AC side also feeds the pulse load in normal operation when the super capacitor bank is out of service. Finally, a fuel cell supplies different loads in the AC side using a unidirectional AC/DC converter in cases where the grid is disconnected from the system and a fault is applied at the AC microgrid resulting in the disconnection of one or more generation units. Specifications of the system components are summarized in Table 1.

TABLE I

SYSTEM COMPONENT PARAMETERS

\begin{tabular}{c|c|c}
\hline \hline Component & Parameter & Specification \\
\hline & $\mathrm{S}_{\mathrm{N}}$ & $7.5 \mathrm{KVA}$ \\
Generator & $\mathrm{V}_{\mathrm{N}}$ & $208 \mathrm{~V}$ \\
& $\mathrm{~F}_{\mathrm{N}}$ & $60 \mathrm{~Hz}$ \\
& $\mathrm{X}_{\mathrm{L}(\mathrm{pu})}$ & 1.305 \\
\hline Transformer & Connection & $\Delta / \mathrm{Y}_{\mathrm{g}}$ \\
\hline
\end{tabular}




\begin{tabular}{|c|c|c|}
\hline & $\begin{array}{c}\mathrm{S}_{\mathrm{N}} \\
\mathrm{V}_{\mathrm{N}} \\
\mathrm{R}_{\mathrm{eq}}, \mathrm{X}_{\mathrm{eq}} \\
\end{array}$ & $\begin{array}{c}7.5 \mathrm{KVA} \\
208 \mathrm{~V} \\
0.72 \Omega, 2.29 \mathrm{mH} \\
\end{array}$ \\
\hline Supercapacitor bank & $\begin{array}{l}\text { Number of cells } \\
\text { Rated voltage } \\
\text { Rated capacity } \\
\text { Surge voltage } \\
\text { Leakage current }\end{array}$ & $\begin{array}{c}20 \\
320 \\
2.9 \mathrm{~F} \\
340 \\
5.2 \mathrm{~mA}\end{array}$ \\
\hline AC filter 1 & $\mathrm{~L}_{\mathrm{AF}}$ & $4 \mathrm{mH}$ \\
\hline AC filter 2 & $\mathrm{~L}_{\mathrm{AF}}$ & $3 \mathrm{mH}$ \\
\hline AC filter 3 & $\mathrm{~L}_{\mathrm{AF}}$ & $0.4 \mathrm{mH}$ \\
\hline Transmission Line & $\begin{array}{l}\mathrm{r}_{1}, \mathrm{r}_{0} \\
\mathrm{l}_{1}, \mathrm{l}_{0} \\
\mathrm{c}_{1}, \mathrm{c}_{0}\end{array}$ & $\begin{array}{c}0.0015 \Omega / \mathrm{Km}, 0.03 \Omega / \mathrm{Km} \\
0.03 \mathrm{mH} / \mathrm{Km}, 0.1 \mathrm{mH} / \mathrm{Km} \\
3 \mathrm{nF} / \mathrm{Km}, 2 \mathrm{nF} / \mathrm{Km}\end{array}$ \\
\hline
\end{tabular}

Bus 2
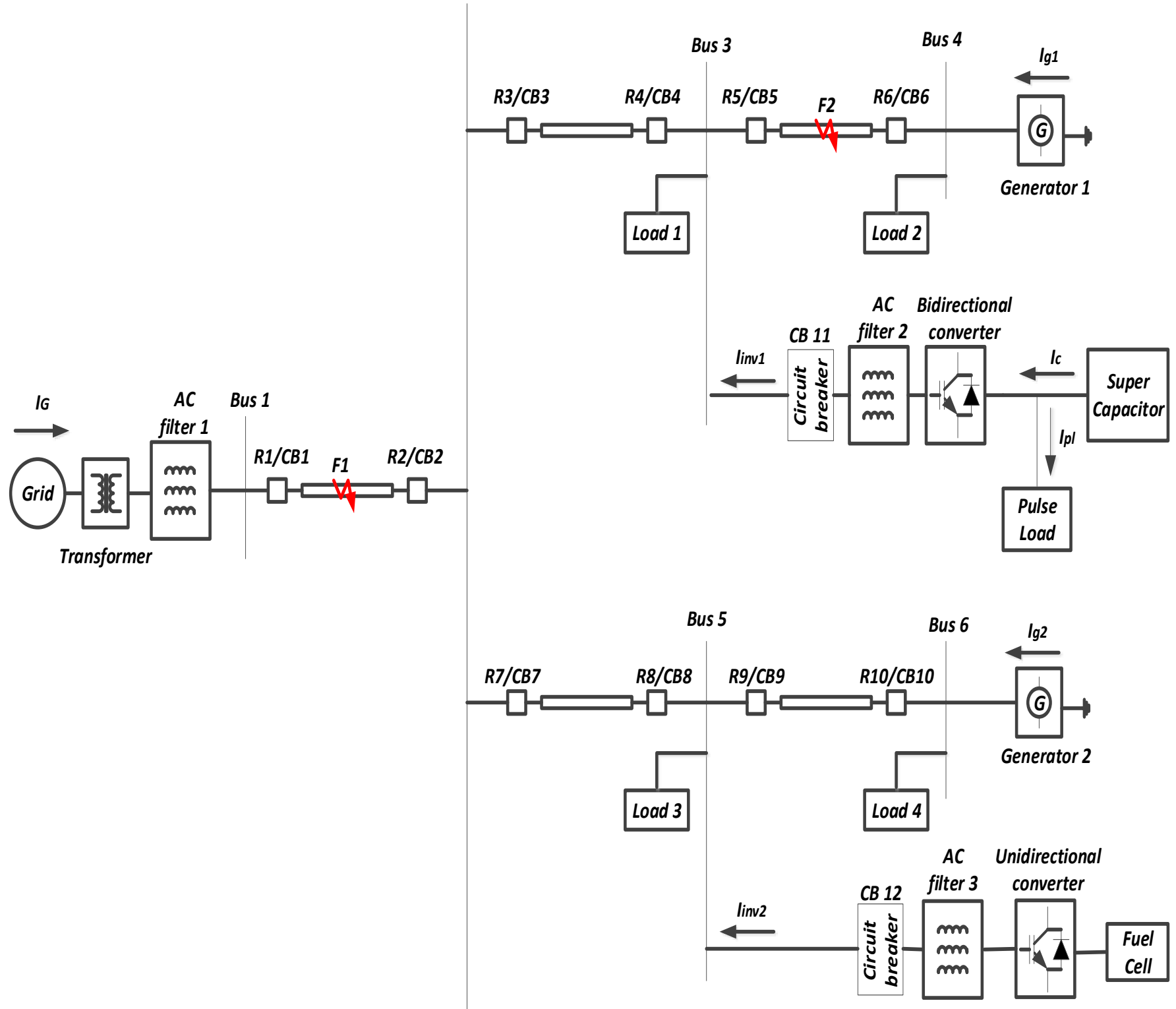

Fig. 1. Microgrid under Study 


\section{Proposed Protection Algorithm}

This section describes the logic algorithm of the relays during the different modes of operation under study namely grid connected mode, islanded mode with communication, and islanded mode with loss of communication. As can be seen in Fig. 2, the logic embedded into the relays in order to sense several of types of faults contains two settings of operation one corresponding to the Higher Setting and another corresponding to the Lower Setting. The higher setting operates at grid and islanded mode with loss of communication, while the lower setting is activated during the islanded mode with communication. Shifting between these two settings occurs as a result of a command signal coming from the point of common coupling (PCC) of the microgrid with the main grid through communication link which is referred to as "Islanded" in Fig. 2. In the Higher Setting, the relay is configured to trip the circuit breaker at a high group of measured currents, whereas in the Lower Setting the relay is configured to trip the circuit breaker at a lower group of input currents. For a viable practical implementation of the proposed protection scheme, the commonly accepted IEC 61850 communication framework could be applied. This emerging international standard provides an efficient and reliable interoperability framework between different field devices in protection applications. For that, the Generic Object Oriented Substation Event (GOOSE) messaging protocol will be utilized to send control messages from the PCC to the system's IEDs in order to shift their settings accordingly. IEC 61850 GOOSE messages are broadcast layer 2 messages of the OSI model that enable fast publish/subscribe message exchange between end devices within a quarter cycle. It is also important to realize the presence of Merging Units (MUs) at both ends of a transmission lines. These merging units will digitize current measurements at the source and broadcast them over the designated network in the form of IEC 61850 Sampled Measured Values (SMV) messages. In this study, we are assuming that all IEDs and MUs are on the same local area network (LAN), however, special router configuration can be applied to exchange messages over wide area networks (WANs) [23]. 
The mathematical equations that can describe the proposed protection technique is explained in the following part. Equation (1) gives the operation of the logic circuit of the relay at trigger high $\left(I_{T H}\right)$ that represented higher settings, when the system operates at grid connected or at islanded mode when the communication fails.

$$
I_{T H}=\left\{\begin{array}{cc}
1 & \left(I_{f} \geq I_{G}+I_{m}\right)+\left(I_{f} \geq I_{S C}+I_{m}\right) \\
0 & \text { otherwise }
\end{array}\right.
$$

Fig. 2. Logic Diagram of the High and Low Relay Settings

Equation (2) describes the logic of the relay at islanded mode of operation when the communication is available in the system. At this case, the relay will produce $\left(I_{T L}\right)$ and adjusted at lower settings.

$$
I_{T L}=\left\{\begin{array}{cc}
1 & \left(I_{f} \geq I_{m}\right) . \text { Islanded } \\
0 & \text { otherwise }
\end{array}\right.
$$

The relay will send a trip signal to the circuit breaker whether $\left(I_{T H}\right)$ or $\left(I_{T L}\right)$ achieved as indicated in equation (3):-

$$
\text { Trip signal }=I_{T H}+I_{T L}
$$

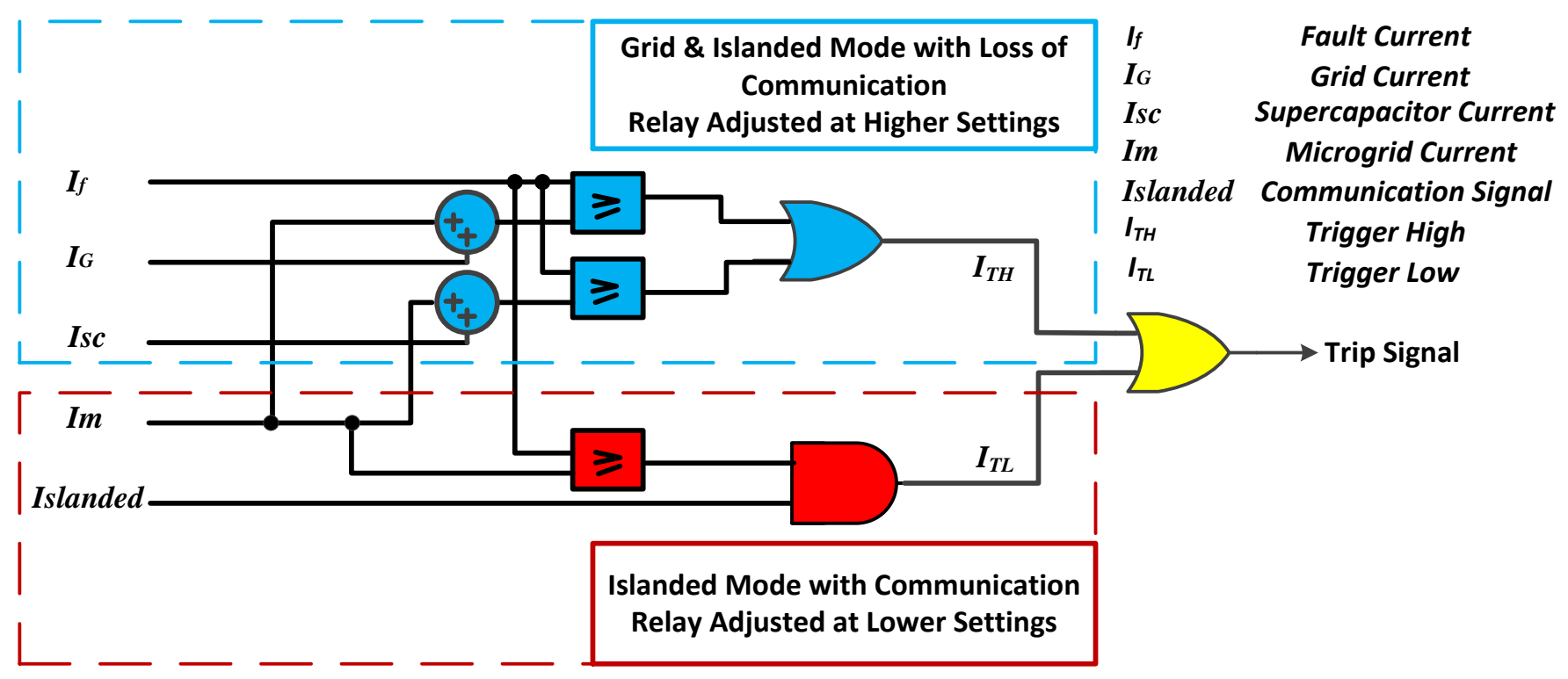


Fig. 3. Shows the flowchart of the proposed protection algorithm. At grid connected mode, the current at each terminal of the transmission lines is measured. When the fault takes place at the microgrid, the fault can be cleared whether the relay settings is adjusted at high or low settings since the fault will be fed mainly from grid. If the fault occurred at the point of common coupling (PCC) with microgrid, the relay will a trip signal to the circuit breaker when $\left(I_{f} \geq I_{G}+I_{m}\right)$ and isolate the fault zone. After that, the mode of operation changes to islanded and the communication plays an important role to determine the relay settings level.

Fig. 3. Flowchart of the Proposed Protection Algorithm

When the communication is available, the relay can update its settings to lower settings and at fault clearing condition $\left(I_{f} \geq I_{m}\right)$, the circuit breaker isolates the faulted part from the system. When the communication is lost, due to a cyber-attack for example, the relay remains at high settings and the previous condition is not satisfied. For this case and when the fault occurs, according to the type of fault,

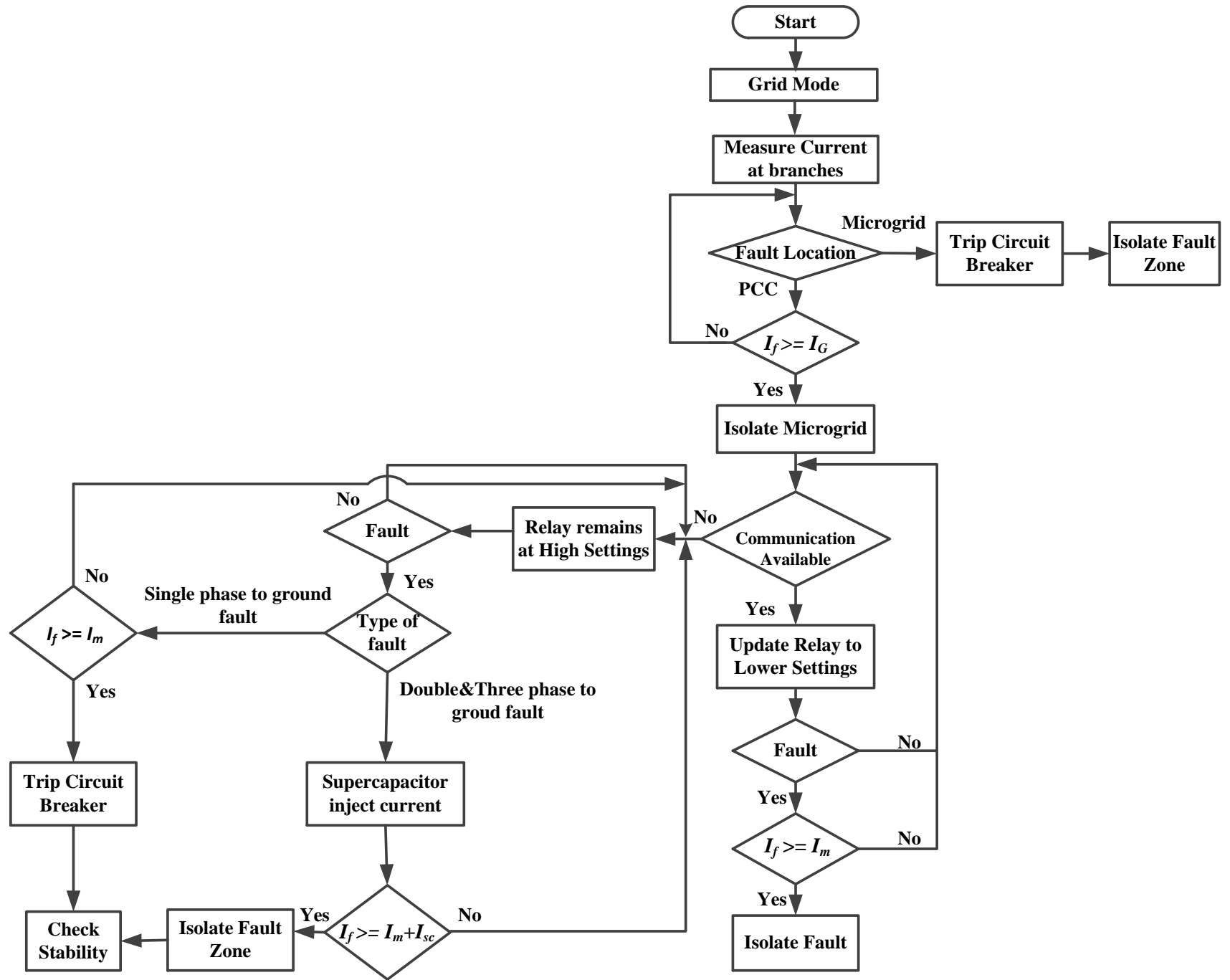

the current can be fed and relay reach to the setting value. If the applied fault was single line to ground fault, the microgrid can contribute to the fault current and the faulted zone is detected and isolated from the 
system. In order to detect three or double phase to ground fault, the supercapacitor can compensate the required current to the relay and isolate the fault. Whether the supercapacitor's state is charging or discharging, it can feed the relay with the current and trip circuit breaker when $\left(I_{f} \geq I_{m}+I_{s c}\right)$ The stability of the overall system is checked to ensure that the frequency and voltages at AC and DC sides are stable especially when the fault happened and pulsed load is turned on.

\section{A. Grid Connected Mode of Operation}

The microgrid in this case is assumed to be operating in the grid connected mode. When a fault occurs in any of the transmission lines within the AC microgrid, high short-circuit currents are expected to flow in the place of the fault reaching values between 6-7 times of the rated current value. In this case, the relays are adjusted to the Higher Setting.

\section{B. Islanded Mode of Operation}

It is assumed here that the microgrid has been disconnected from the main grid due to a fault F1 shown in Fig. 1. The microgrid is thus operating in islanded mode. The relay at the PCC senses this shift and issues a control signal to all relays to shift to the Lower Setting. The setting of the relays are therefore adjusted to be between 1.5-2 times of the rated current at this mode. This is due to the fact that the microgrid cannot feed the fault with the same capacity as the main grid. Also the power electronic devices that are used for the fuel cell reduce the amount of the short circuit current. Changing from the grid setting to the microgrid setting can be performed using the Islanded signal shown in Fig. 2. Reliable communication between the PCC and the relays in the microgrid is therefore critical for shifting between relay settings for proper location and isolation of the fault.

\section{Islanded Mode of Operation with Loss of Communication}

The system configuration here is the same as that in B, however, it is assumed that communication is lost between the PCC and the microgrid's relays. Therefore, the settings of the relays will not shift to the proper setting (Lower Setting) and will render them unable of sensing faults. In this event, energy storage devices can be added to solve the problem of communication failure. Loss of communication in a system is when a system's components that act control commands stop responding to commands or behave in unconventional ways due to a system malfunction or a malicious cyber-attack [24]. In fact, as explained in [24], loss of communication may be due to several reasons like failure of communication equipment, such

as a network switch, or noise on a communication channel causing transmission errors or data unavailability. Communication might also be lost due to a failure in of central systems (e.g. servers) at substations and microgrids control centers causing unreliable sending and reception of control signals. Last but not least, loss of communication might be due to malicious efforts such as cyber-attacks. A denial of 
service (DoS) attack is when the attacker attempts to prevent authorized users or machines from accessing a service. One way of doing this is to disrupt or exploit the services of the relay.

In adaptive protection operations, a DoS attack might disrupt the operation of IEDs by transmitting malicious code to the targeted IED or IEDs that writes over-sized data to cause a buffer overflow [25]-[26]. The attacker can choose to exploit common services on a relay. They can do this by opening multiple sessions on either the File Transfer Protocol (FTP), or Telnet services and keeping them idle all the time preventing the relay from responding to critical grid events such as protection. It is also explained in [26] that DoS could be the result of a flooding attack to delay message delivery past the critical flooding rate by congesting the channel and exhausting the computation resources of the communicating nodes.

When the communication fails in the islanded mode of operation, the setting of the relay is not adjusted to the lower setting and the relay is adjusted to trip at higher setting. The capability of the islanded microgrid is not enough to reach to this setting. A supercapacitor bank is used to solve this problem. This supercapacitor bank can compensate for the difference between the grid and islanded mode and will contribute to the fault current raising it to a value which is sensed by the high relay setting detect and isolate the fault. Therefore, the proposed protection algorithm will be able to survive communication failures.

\section{CONTROL OF SUPERCAPACITOR-BASED MiCROGRID}

\section{A. Supercapacitor-Pulse Load Microgrid}

A supercapacitor is a storage device which is capable of storing electrical energy directly between two conducting electrodes. The capacitance and energy density of a supercapacitor are thousands of times larger than a conventional electrolytic capacitor. A supercapacitor is also known as a double-layer capacitor since it can store energy across the double layers formed at the interface between an electronically conducting carbon and the electrolyte. A supercapacitor is known to have high power density, low internal resistance, and high life cycle [27-30]. In order to increase the energy density of a supercapacitor, high surface-area materials such as activated carbon are used. High power energy storage is commonly used in many systems such as telecommunications, shipboard and spacecraft power systems. In these applications, there are various types of loads that show high instantaneous power requirement but require a relatively low average power. These types of loads are referred to as pulse loads. The duration of such loads ranges typically from

hundreds of milliseconds to seconds with different power levels. In microgrid applications, the high instantaneous power of a pulse load can cause considerable power disturbances and thermal problems. Introducing a fast response high power storage system, such as a supercapacitor bank, with the appropriate power electronic and control, will improve the performance of the system drastically [31-35]. 
Besides the function of the supercapacitor in the normal operation for supplying the pulse load, it has been used in this paper to enhance the protection system resiliency to communication failures. The control scheme of the microgrid has been modified to allow the supercapacitor to contribute the fault current while there are no enough resources to feed the fault current, which is the case of the microgrid's islanded mode of operation. This is useful in case the protection algorithm is unable update relays' setting due to communication failure as discussed earlier.

\section{B. Autonomous Control of Supercapacitor AC/DC Converter}

The supercapacitor is typically designed to supply a periodic pulse load in a system. This supercapacitor is coupled with the AC side through a bidirectional AC-DC voltage source converter (VSC) as indicated in Fig. 4. An improved control algorithm with only one mode of operation has been proposed in this paper to allow the microgrid to work properly during the normal and faulty operations whether in grid-connected on islanded mode of operation. Thus the controller needs not to rely on any communication signal to detect the mode of operation of the microgrid as it is autonomous in nature. In the normal operation, the supercapacitor will charge from the AC side during the off-time pulse load, and then discharge during the on-time pulse load to supply the load demand. Moreover, the controller is designed to allow the DC microgrid to regulate the AC side frequency and voltage during the islanded mode of operation.

During the faulty operation, the controller will direct the microgrid to enhance the system stability and will help the system restore after isolating the fault. This is the controller's role if either the system has enough resources to supply the fault current such as grid-connected operation, or the protection relays were able to update their settings based on data communication. In case of the system does not have enough resources and the communication was unavailable, the controller will force the microgrid to compensate the fault current and achieve fault isolation. This function will enhance the protection system resiliency against communication failures.

The details of the control scheme are indicated in Fig. 4. Two control loops are implemented for active and reactive power flow control to achieve both frequency and voltage regulation. The supercapacitor reactive power is controlled, based on $I_{q_{-} r}$, to keep the AC side voltage at a specified value using a PI controller. The active power reference component $\left(I_{d_{-} r}\right)$ is generated using two PI controllers. The first is responsible for regulating the AC side frequency to be within the acceptable limit, whereas the second is used to keep the supercapacitor DC voltage within the specified level. Using the AC side frequency as a signature to the active power flow allows the supercapacitor to supply large currents during the fault and contribute to the fault current during loss of communication situations.

Based on the inverse Park transformation the reference three phase currents $\left(I_{a_{-} r}, I_{b_{-} r}\right.$, and $\left.I_{c_{-} r}\right)$ are estimated from the $d q 0$ rotating reference frame currents. The angle between the two reference frames and 
the system frequency are estimated from three-phase Phase Locked Loop block (PLL). The $a b c$ reference currents are compared with the actual measured currents and applied to the pulse width modulation (PWM) scheme to generate the switching signals of the inverter. The hysteresis band current control is considered in this work because of its simplicity of implementation and fast response current loop. It also doesn't need any knowledge of the load parameters [36]-[37].

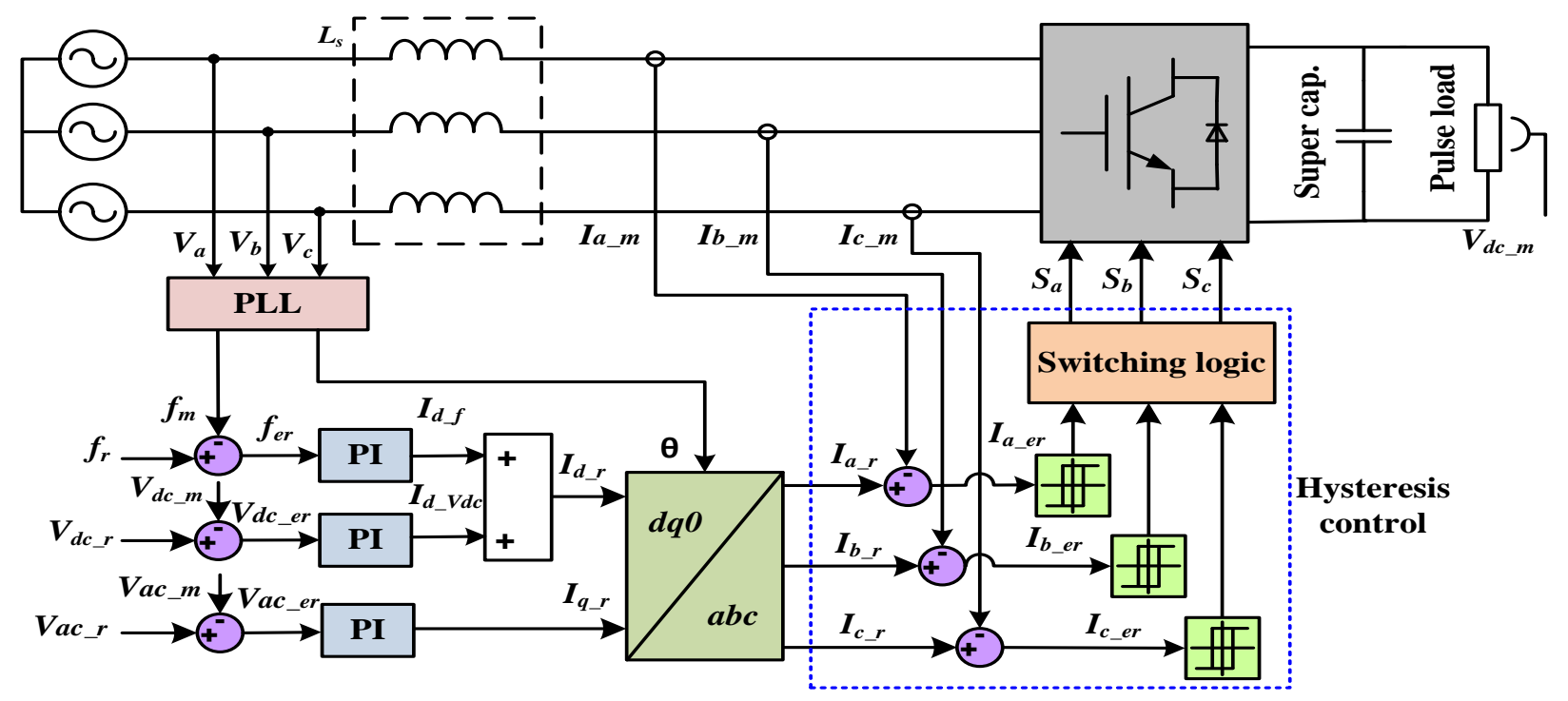

Fig. 4. Autonomous AC/DC Converter Controller

Mathematical formulation of the suggested control to achieve the protection scheme can be explained in the following formulas:-

Frequency error $\left(f_{e r}\right)$ is the difference between the reference $\left(f_{r}\right)$ and measured frequency $\left(f_{m}\right)$ :-

$$
f_{e r}=f_{r}-f_{m}
$$

Equations (5), (6) described the AC and DC voltage errors.

$$
\begin{gathered}
V_{d c_{-} e r}=V_{d c_{r}}-V_{d c_{m}} \\
V_{a c_{-} e r}=V_{a c_{-} r}-V_{a c_{-} m}
\end{gathered}
$$

The frequency error introduced to PI controller with $k_{p_{-} f}$ and $k_{i_{-} f}$ parameters and produced direct current component for regulating the system frequency.

$$
I_{d_{-} f}=f_{e r} \times \frac{k_{p_{-} f} s+k_{i_{-} f}}{s}
$$

The error in DC and AC voltages controlled by PI controller and produced the required direct current component to regulate them as shown in equations (8), (9):-

$$
I_{d_{-V d c}}=V_{d c_{e r}} \times \frac{k_{p_{-} V d c} s+k_{i-V d c}}{s}
$$




$$
I_{q_{-r}}=V_{a c_{-} e r} \times \frac{k_{p_{-} V a c} s+k_{i_{-} V a c}}{s}
$$

The output of the controller of frequency and DC voltage are combined together and produce the reference of direct current $\left(I_{d \_r}\right)$ :-

$$
I_{d_{-} r}=I_{d_{-} f}+I_{d_{-} V d c}
$$

Equation (11) described the transformation from dq to abc axises:-

$$
\left[\begin{array}{c}
I_{a_{-} r} \\
I_{b_{-} r} \\
I_{c_{-} r}
\end{array}\right]=\left[\begin{array}{ccc}
\cos \theta & \sin \theta & 1 \\
\cos (\theta-120) & \sin (\theta-120) & 1 \\
\cos (\theta+120) & \sin (\theta+120) & 1
\end{array}\right]\left[\begin{array}{c}
I_{q_{-} r} \\
I_{d_{-} r} \\
I_{0}
\end{array}\right]
$$

The error of the current signals in three phase current $\left(I_{a b c_{-} e r}\right)$ is the difference between the reference $\left(I_{a b c_{\_} r}\right)$ and the measured values $\left(I_{a b c_{-} m}\right)$.

$$
I_{a b c_{-} e r}=I_{a b c_{-} r}-I_{a b c_{-} m}
$$

$I_{a b c_{\_} e r}$ is feed to Hysterises current controler to track the current reference $I_{a b c_{-} r}$

\section{RESUltS AND DisCUSSION}

\section{A) Simulated Cases}

\section{Case 1:- Grid Connected Mode of Operation}

In this case a three-phase to ground fault (F2 in Fig. 1) has been applied in the transmission line between busses 3 and 4 while the microgrid was in grid connected mode of operation. The system performance during this fault is indicated in Fig. 5. As it can be noticed, the fault occurred at $\mathrm{t}=6$ seconds and cleared instantaneously. In this case, the utility helped to maintain the system's frequency stable during and after the fault, as shown in Fig 5(a). Fig. 5(b) shows the pulse load $\left(\mathrm{I}_{\mathrm{pl}}\right)$, supercapacitor $\left(\mathrm{I}_{\mathrm{c}}\right)$, and inverter $\left(\mathrm{I}_{\text {inv1 }}\right)$ currents. During the off-time pulse load, the capacitor will be charging from the AC side, whereas during the on-time pulse load the supercapacitor will be the major feeder to the pulse load, as indicated in Fig. 5(c). The AC side will still be present to feed the pulse load in case the supercapacitor went out of service. Fig 5(d) and (e) show the high fault current values of 32 Amps which is mainly being contributed to by the grid. As anticipated for the grid connected mode, the fault current is almost more than 6 times the rated AC current and thus the protection devices where able to detect and isolate the faults successfully. 


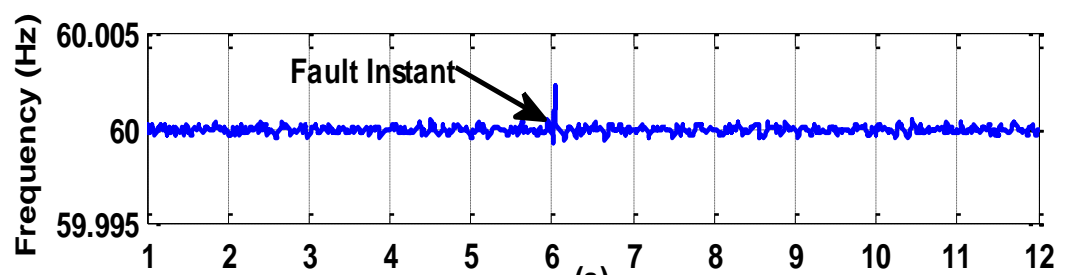

(a)

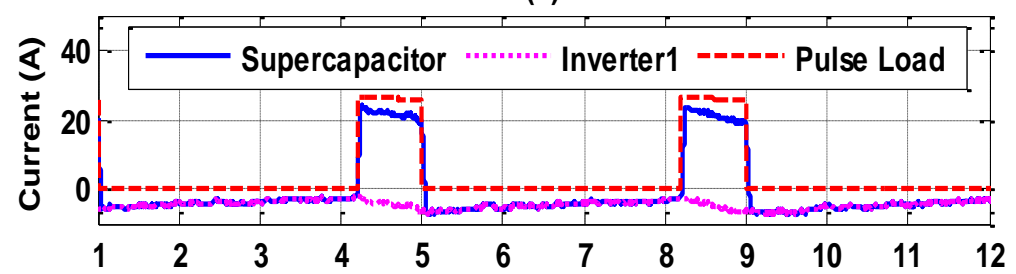

(b)

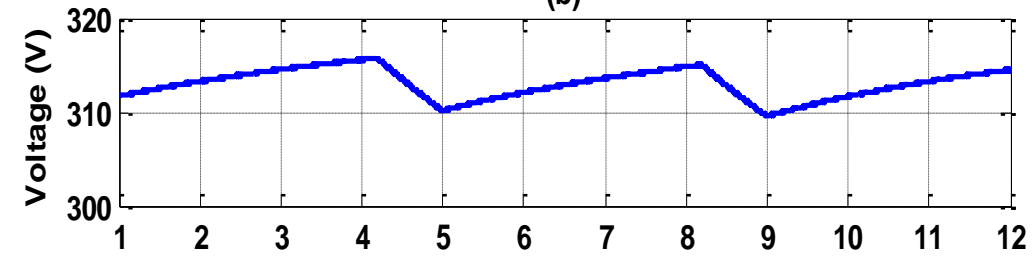

(c)

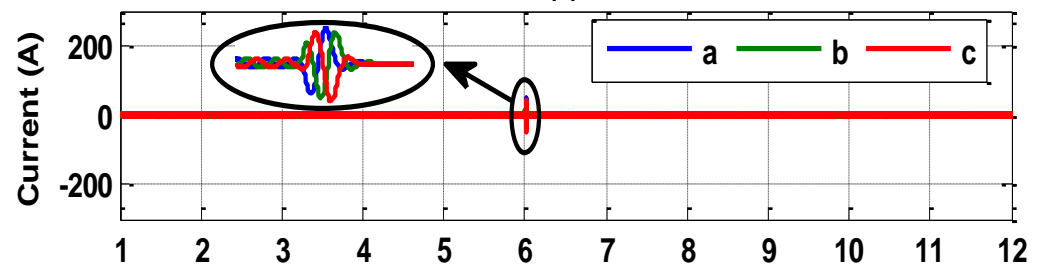

(d)

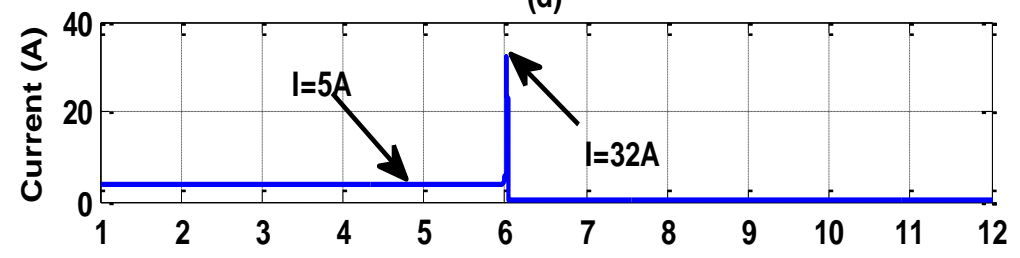

(e)

Time (s)

Fig. 5. System performance during fault at grid connected mode of operation: (a) frequency, (b) supercapacitor current, inverter current, and pulse load current, (c) supercapacitor DC voltage (d) three-phase currents in the faulted transmission line, and (e) RMS current in the faulted transmission line

\section{Case 2:- Islanded Mode of Operation with Communication}

In this situation, a three-phase-to-ground fault (fault F1 in Fig. 1) occurred at time $t=1.5$ seconds, in the transmission line connecting the main grid to the microgrid under study. As a result, relay R1 will send a trip signal to circuit breaker CB1 to isolate the microgrid. The microgrid successfully shifted to a stable islanded mode by adjusting its overall frequency back to the normal condition after fault, as shown in Fig. 6(a). A small disturbance, within acceptable limits, in the output voltages of the sources $\left(\mathrm{V}_{\mathrm{G}}, \mathrm{V}_{\mathrm{g} 1}, \mathrm{~V}_{\mathrm{g} 2}, \mathrm{~V}_{\mathrm{inv1}}\right.$ and $\mathrm{V}_{\text {inv2 }}$ representing the voltages at busses 1, 4, 6, 3 and 5, respectively), is noticed in Fig. 6(b). Fig. 6(c) shows a spike in $\mathrm{I}_{\mathrm{G}}$ due to the fault and this current drops to zero after clearing the fault by disconnecting the microgrid. 

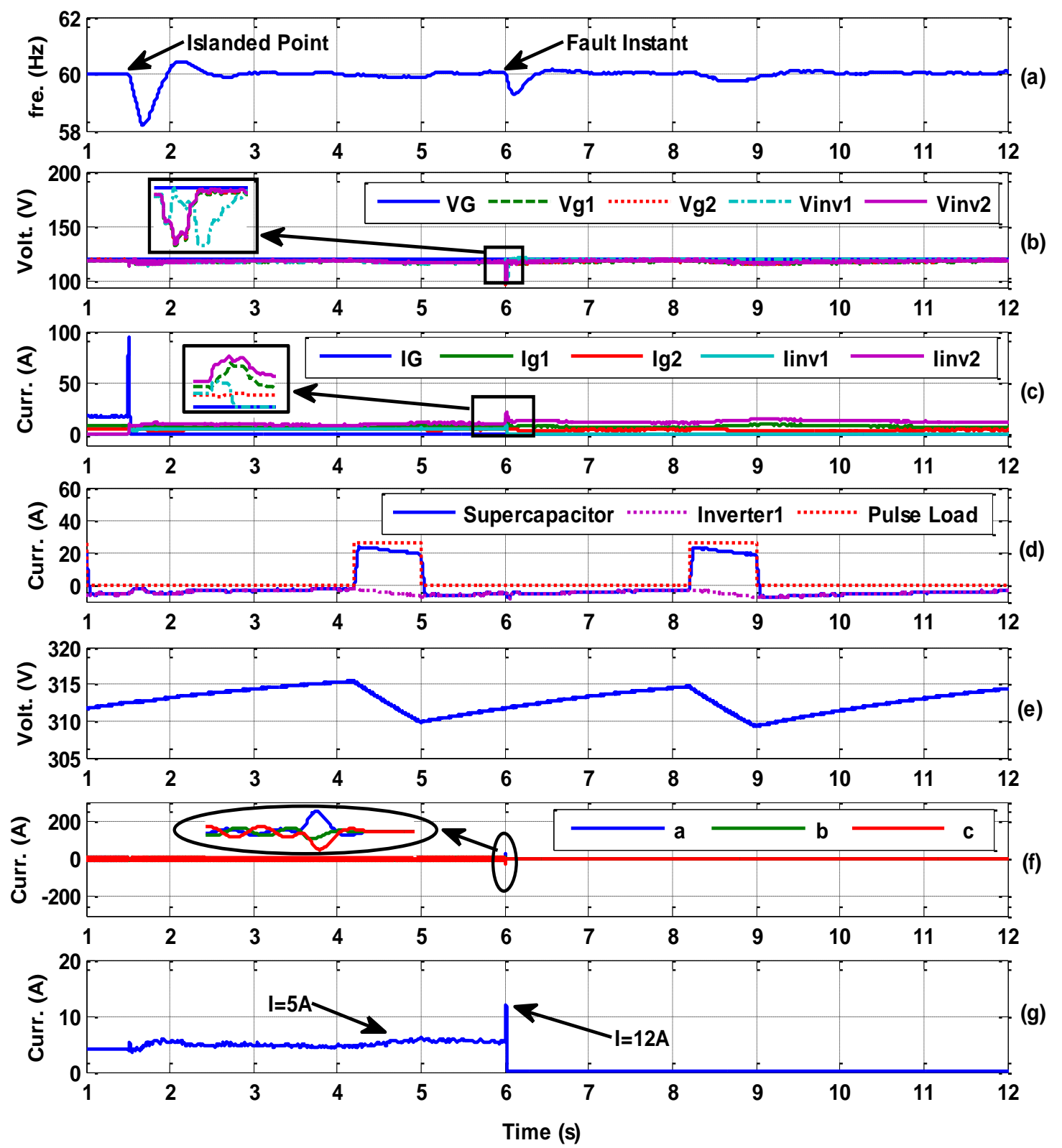

Fig. 6. System performance during fault at microgrid operation with communication (a) frequency, (b) output voltage of each source, (c) output current of each source, (d) supercapacitor current, inverter1 current, and pulse load current,, (e) supercapacitor DC voltage, (f) three-phase current in the faulted transmission line, and (g) RMS current in the faulted transmission line

An increase in the generator's currents $\left(\mathrm{I}_{\mathrm{g} 1}\right.$ and $\left.\mathrm{I}_{\mathrm{g} 2}\right)$ is noticed in order to compensate for the current which was previously supplied mainly by the grid. Fig. 6(d) and (e) show the supercapacitor-pulse load microgrid performance parameters which exhibit stable performance during the islanding instant. Finally, Fig. 6(f) and (g) indicate the minor change in the AC current at transmission line connecting busses 3 and 4 after the fault.

During the islanded operation, another three-phase-to-ground fault occurred at $\mathrm{t}=6$ seconds, in the middle of transmission line connecting buses 3 and 4. Based on the available communication infrastructure in the 
system, relay R5 settings is adjusted to the lower setting and thus was capable of detecting the fault and tripping CB5 accordingly. Fig 6(a) shows the microgrid frequency recovery after the fault incident.

As can be noticed the system is showing stable performance during and after the fault with disturbances within the specified limits of microgrids operation. The sources voltages $V_{\mathrm{g} 2}, \mathrm{~V}_{\mathrm{inv1}}$ and $\mathrm{V}_{\mathrm{inv} 2}$ dropped at the fault incident and recovered after clearing the fault, as shown in Fig. 6(b). After the fault was cleared, Fig 6(c) shows that $I_{g 1}$ dropped to zero since generator G1 was isolated from the system. Current $I_{g 2}$ increased to feed the loads accordingly. It can be noticed in Fig. 6(d) and (e) that the supercapacitor was not used to feed the fault current due to the adaptation process for R5 setting to its lower setting. Fig. 6(f) and (g) show that the AC current in transmission line where fault F2 occurred increased significantly from 5 to 12 A during the fault instance. It can be noticed also, that the fault current level is less than that appeared in the grid connected mode (32 A) as was discussed earlier.

\section{Case 3:- Islanded Mode of Operation without Communication During Supercapacitor Charging}

In this case, fault F2 occurred during the off-time of the pulse load (i.e. charging of the supercapacitor). Due to the assumption of the communication failure, relay R5 will not be able to switch to the lower settings. In this case, as shown in Fig. 7(b), the supercapacitor compensate the fault current until it reach to the higher setting of the relay (32 A) as indicated in Fig. 7(c). This resulted in relay R5 sensing the fault

and thus isolating it accordingly. After clearing the faulted region the system restored and shows stable performance. 


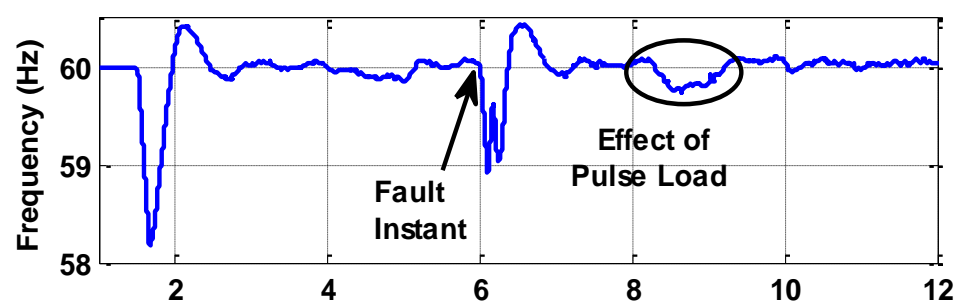

(a)

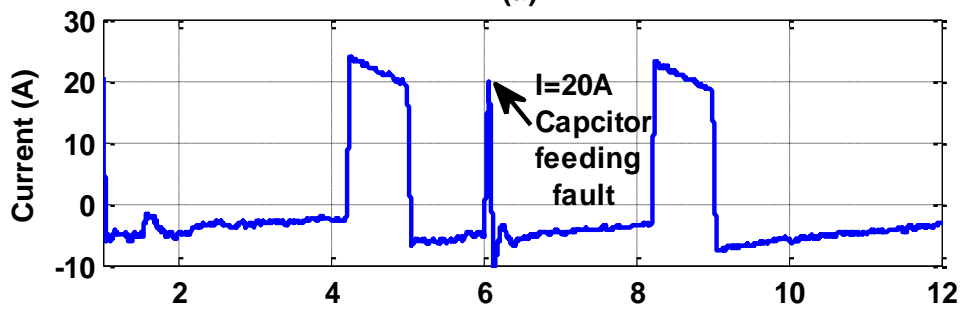

(b)

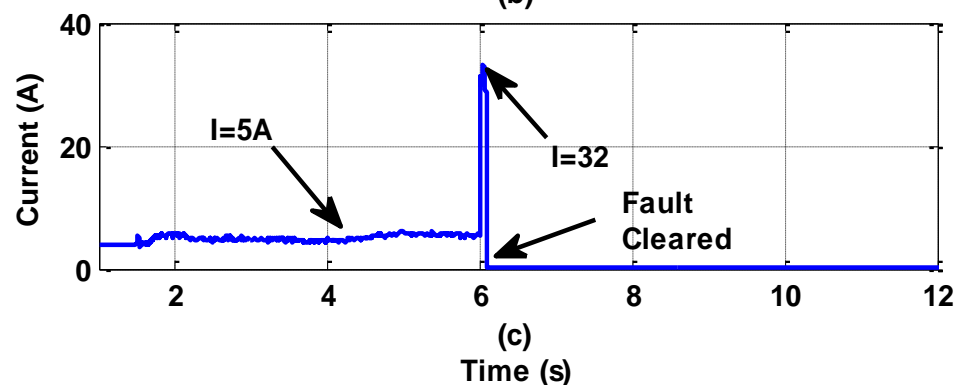

Fig. 7. System performance during fault at microgrid operation without communication (a) frequency, (b) supercapacitor current, and (c) RMS current in the faulted transmission line

Case 4:- Islanded Mode of Operation without Communication during Supercapacitor Discharging

\subsection{Oversized Supercapacitor to Feed the Fault and Pulse Load Currents}

This solution is recommended in case of critical pulse loads that cannot accept any instantaneous supply interruption. In this case, the supercapacitor needs to be designed to supply both the pulse load and the fault current requirements. The system performance during a fault F2 at this circumstances is described in Fig. 8 . As indicated in Fig. 8(b), the fault occurred during the discharging of the supercapacitor phase of the pulse load period. It is noted that due to communication failure, relay R5 will not switch to the lower settings and the supercapacitor quickly contributed to the fault current while still covering the pulse load as reflected on the pulse load current in Fig 8(c). The maximum current drawn from the supercapacitor in this case is 45 Amps which is required to feed the fault and the pulse load simultaneously. Fig. 8(d) shows that the fault current drastically increased from 5 Amps to 32 Amps. This resulted in relay R5 sensing the fault and thus isolating it accordingly as explained in the normal condition. 


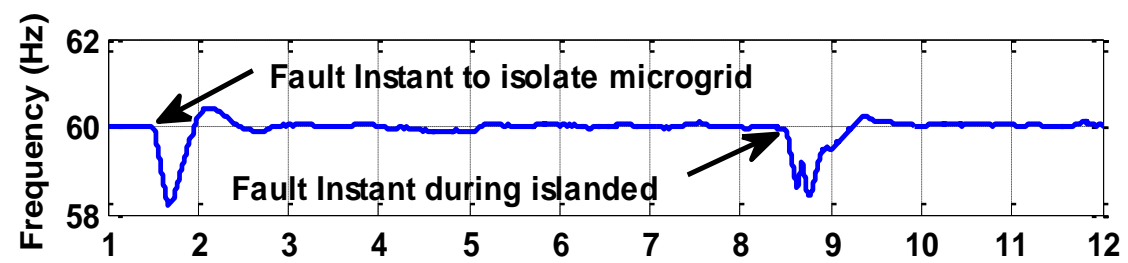

(a)

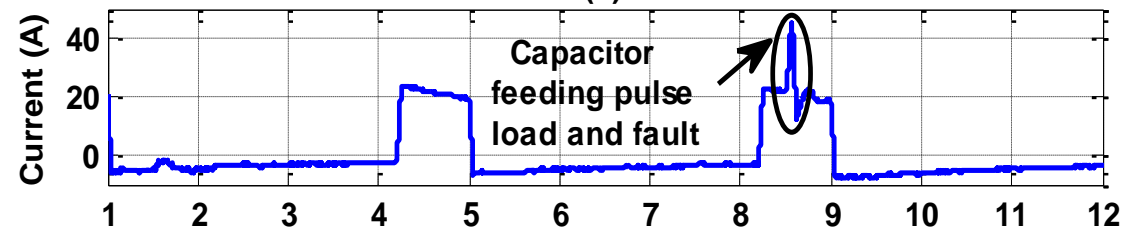

(b)

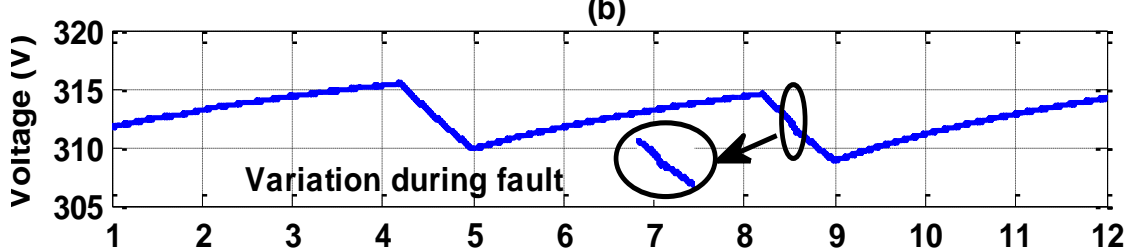

(c)

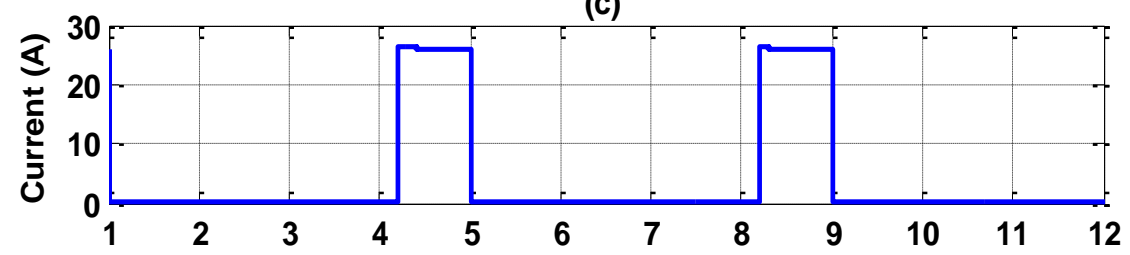

(d)

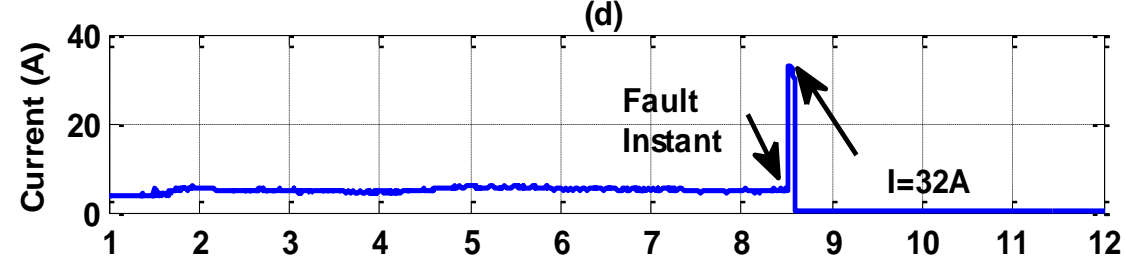

(e)

Time (s)

Fig. 8. System performance during fault at microgrid operation without communication (a) frequency, (b) supercapacitor current, (c) supercapacitor DC voltage, (d) pulse load current, and (e) RMS current in the faulted transmission line

\subsection{Disconnecting the Pulse load During the Fault}

This section presents the cheap solution of this problem which is useful in case of the pulse load can accept the instantaneous power interruption. Similar to the previous case, fault F2 occurred during the ontime period of the pulse load. It is noticed in Fig. 9(b) that, due to communication failure relay R5 will not switch to the lower settings and the supercapacitor quickly contributed to the fault current. However in this case, the pulse load was disconnected for a short period of time during the fault in order to reduce the amount of current drawn from the supercapacitor which reached a maximum of 27 Amps in this case. To disconnect the pulse load, the rate of change of the supercapacitor's voltage was monitored to detect a small notch in the DC voltage indicating the fault as shown in Fig. 9(c). This in fact does not depend on any communication command or any conventional change in frequency or AC voltage signature. The pulse load interruption is described in Fig. 9(d). Fig. 9 (e) shows that the fault current drastically increased from 5 
Amps to 32 Amps. It is worth to mention that this solution is applicable to some types of uncritical loads. However, critical pulse loads, that cannot be disconnected and thus will fall into the category explained in section D.1. These pulsed loads could be present on ship power systems, which can be electrically treated as islanded microgrids as indicated in [38]. Additionally, pulsed loads do exist in regular power system microgrids (other than ships). These pulsed loads could be large cranes, radar systems, welding machines or an electric vehicle park with simultaneous fast charging of large number of vehicles [39].
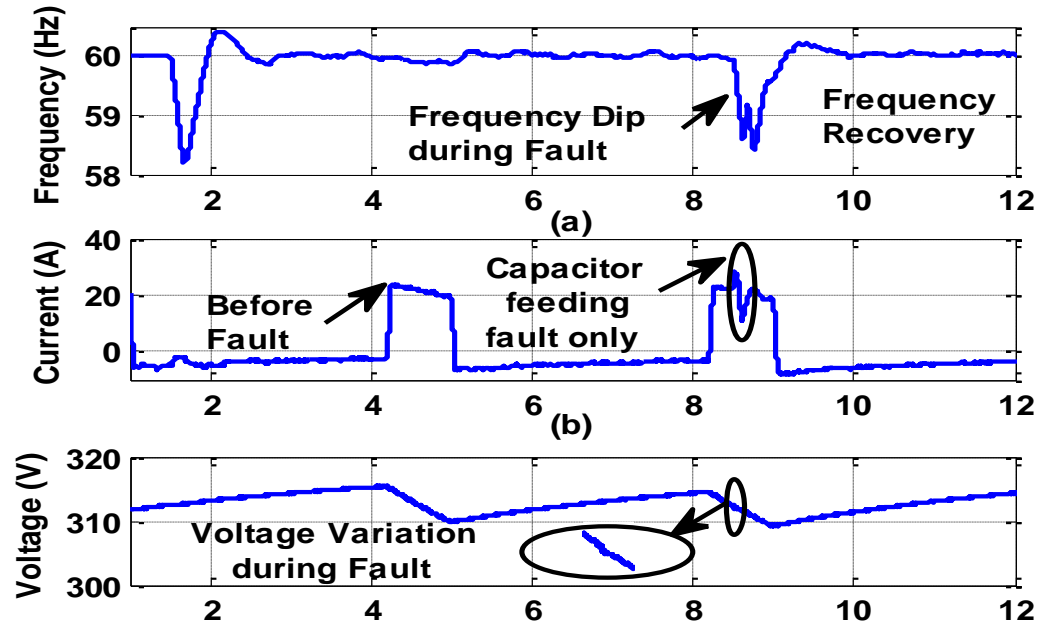

(c)
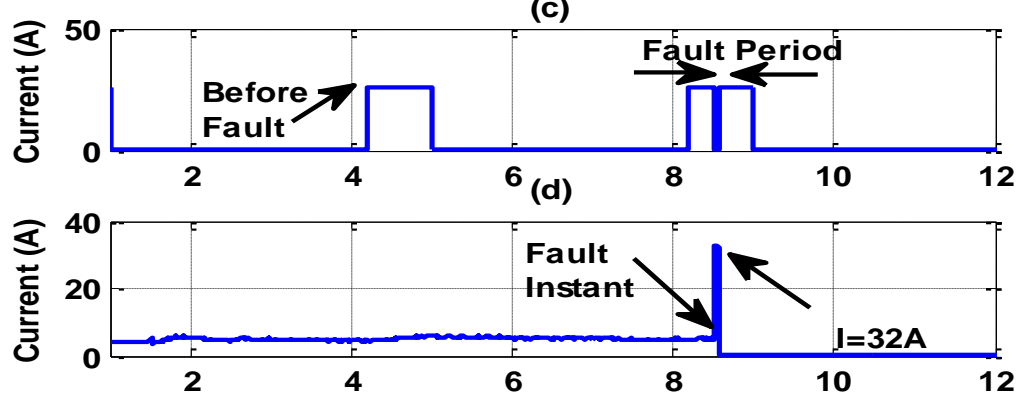

(e)

Fig. 9. System performance during fault at microgrid operation without communication (a) frequency, (b) supercapacitor current, (c) supercapacitor DC voltage, (d) pulse load current, and (e) RMS current in the faulted transmission line

B) Performance Evaluation of the Proposed Protection Schemes under Different Types and Magnitudes of Fault Currents

TABLE II

PERFormance of THE ProteCtion SCHEME UnDER DifFERENT TyPES OF FAULTS 


\begin{tabular}{|c|c|c|c|c|c|c|c|c|c|c|c|c|c|c|c|}
\hline \multirow{3}{*}{$\begin{array}{c}\text { Fault } \\
\text { Type }\end{array}$} & \multirow{3}{*}{$R_{f}(\Omega)$} & \multirow{3}{*}{$\begin{array}{c}\text { RS Csae } \\
1\end{array}$} & \multirow{3}{*}{ RS Case 2} & \multirow{2}{*}{\multicolumn{3}{|c|}{ Case 3}} & \multicolumn{6}{|c|}{ Case 4} & \multirow{3}{*}{$I_{P L}(\mathrm{~A})$} & \multirow{3}{*}{$\begin{array}{c}\Delta I_{c} \\
\text { Case } 4.1 \\
(\%) *\end{array}$} & \multirow{3}{*}{$\begin{array}{c}\Delta I_{c} \\
\text { Case } 4.2 \\
(\%) *\end{array}$} \\
\hline & & & & & & & \multicolumn{3}{|c|}{ Case 4.1} & \multicolumn{3}{|c|}{ Case 4.2} & & & \\
\hline & & & & $I_{c}(\mathrm{~A})$ & $I_{m}(\mathrm{~A})$ & RS (A) & $I_{c}(\mathrm{~A})$ & $I_{m}(\mathrm{~A})$ & RS (A) & $I_{c}(\mathrm{~A})$ & $I_{m}(\mathrm{~A})$ & RS (A) & & & \\
\hline ABCG & 2 & 32 & 12 & 20 & 12 & 32 & 45 & 12 & 32 & 27 & 12 & 32 & 23 & 95.65 & 17.39 \\
\hline \multirow{2}{*}{ BCG } & 1.8 & 30 & 10 & 15 & 15 & 30 & 41 & 15 & 30 & 26 & 15 & 30 & 23 & 78.26 & 13.04 \\
\hline & 3 & 21 & 8 & 10 & 11 & 21 & 36 & 11 & 21 & 24 & 11 & 21 & 23 & 56.52 & 4.3 \\
\hline AG & 1 & 12 & 6 & 0 & 12 & 12 & 23 & 12 & 12 & 23 & 12 & 12 & 23 & 0 & 0 \\
\hline
\end{tabular}

$R_{f}=$ Fault Resistance $; R S=$ Relay Settings; $I_{c}=$ Supercapacitor current contribution; $I m=$ Microgrid current contribution; $I_{p l}=$ Current drawn from supercapacitor to feed the pulse load $*(I c-I p l) / I p l$;

The numerical figures in the first row of Table II represent the results of different case studies discussed earlier at three phase to ground fault (ABCG) with $2 \Omega$ fault resistance. The results of the various modes of operation of the microgrid with and without communication discussed above for different types of faults with varying fault resistances at the transmission line that connecting between buses 3 and 4 (F2) are then shown in the subsequent rows. For the case of a three- phase-to-ground fault, a significant decrease in the current drawn from the supercapacitor was observed when the pulse load was disconnected during the fault 
period (from $95.65 \%$ to $17.39 \%$ in the $2 \Omega$ fault resistance case and from $43.47 \%$ to $8.69 \%$ in the $4 \Omega$ fault resistance case). Similarly, in the case of a double-line-to-ground fault (BCG), a decrease in the current drawn from the supercapacitor was observed when the pulse load was disconnected during the fault period (from $78.26 \%$ to $13.04 \%$ in the $2 \Omega$ fault resistance case and from $56.52 \%$ to $4.3 \%$ in the $3 \Omega$ fault resistance case). Therefore, the temporary disconnection of the pulse load, whenever possible, during fault period. That is, when the pulse load is disconnected, the supercapacitor will only be feeding the load. This will not incur any additional costs on the system to install bigger capacitors than the ones already present to protect the system. It is noted that in the formal two faults, the resources in the microgrid without the supercapacitor were incapable of feeding enough current to the fault for the relays to detect it in case of communication failure. This shows that the proposed solution of utilizing a supercapacitor does indeed enhance the reliability of the protection scheme in case of loss of communication. Finally, the AC microgrid generating units were capable of feeding sufficient fault current for fault detection in the case of a single-line-to-ground fault (AG) without assistance from the supercapacitor. This is because the currents produced from this type of faults are usually smaller than the previous fault types. We can see from the table that the current drawn from the supercapacitor did not increase in this case.

\section{C) Analysis on Sizing and Cost of the Supercapacitor}

In order to accommodate for a worst case scenario of having the supercapcitor feed the pulse load $\left(P_{p l}\right.$ $=V_{d c} * I_{p l}=320 * 23=7.3 \mathrm{Kw}$ ), as well as the fault current when the pulsed load is turned on, the following criteria was taken into account when sizing the supercapacitor:

According to reference [17], the energy supplied by supercapacitor is calculated using the following equation:

$$
E=P_{\text {nom }} * t_{\max }
$$

Where $P_{\text {nom }}$ is the nominal power that can be injected from the supercapacitor at the worst case when the generators and fell cell are not operated and when the pulse load is turned on during the fault at the point that is far from the supercapacitor between buses 5 and 6 in Fig. 1, $\left(P_{\text {nom }}=40 \mathrm{Kw}\right) \cdot t_{\max }$ is the time that the supercapacitor feeds the pulsed load $\left(t_{\max }=0.8 \mathrm{Sec}.\right)$.

$$
E=(40 k w * 0.8) /(60 * 60)=8.8 W h
$$

According to reference [40], the capacitance of the supercapacitor is determined using equation (14):

$$
E=\frac{1}{2} C\left(V_{\max }-V_{\min )^{2}}\right.
$$

Where Vmax is the maximum voltage of a supercapacitor bank during a pulse load and Vmin is its minimum voltage. 


$$
\begin{gathered}
8.8=\frac{1}{2} C(314-311.5)^{2} \\
C=2.9 F
\end{gathered}
$$

It can be noted that this capacitance can feed the fault when the pulsed load is turned on. In order to give more analyses on the cost of the proposed algorithm, the cost of the supercapacitor of this case is added and compared with the case of turning on the pulsed load at the event of a fault.

The commercial price of the supercapacitor Model BMOD0058-E016-B02 manufactured by Maxwell [41], is $122.25 \$$. The number of modules that are used are 20 modules. The storage energy per module is 2.1 WH.

The cost of the supercapacitor is $122.25 \$ * 8.8 / 2.1=512.28 \$$

When the pulsed load is turned off and a fault happens, the required power that can be injected by the supercapacitor will decrease thus reducing its size and cost consequently.

$$
\begin{gathered}
E=(32.7 k w * 0.8) /(60 * 60)=7.3 W h \\
7.3=\frac{1}{2} C(314-311.5)^{2} \\
C=2.3 F
\end{gathered}
$$

The cost of the supercapacitor in this case is $122.25 \$ * 7.3 / 2.1=424.96 \$$

Thus, the cost will be reduced by $17.04 \%$ and the capacitance of the supercapacitor will also be reduced by $20.68 \%$ when the pulse load is turned off during the fault.

\section{CONCLUSION}

The work in this paper proposes an adaptive protection scheme for AC microgrid systems which is capable of surviving communication failures by utilizing energy storage devices. This was done using a supercapacitor bank in particular, to contribute enough fault current when the protection relays fail to switch to lower settings. This paper also proposed a new design of an autonomous control algorithm for a supercapacitor's AC/DC converter capable of operating when the microgrid is in both grid-connected and islanded mode. It was shown that the converter's single mode of operation eliminates the reliance on the communicated control command signals to shift the controller between the microgrid's grid-connected and islanded modes of operation. In all simulated cases, the system was able to maintain stable voltage and frequency levels even during extreme cases such as the occurrence of a fault during a peak pulse load period. Several types of faults were simulated and the results demonstrated the resiliency of the proposed protection algorithms against communication outages. It was also shown that, whenever possible, if the pulse load is disconnected temporarily during the fault period, the supercapacitor will feed only the fault 
current. Therefore, in these practical situations, no additional costs are incurred in the system as there will be no need to install larger supercapacitor banks than those already present in the microgrid.

\section{ACKNOWLEDGEMENTS}

This work was partially supported by grants from the Office of Naval Research and the US Department of Energy.

\section{REFERENCES}

[1] A. Mehrizi-Sani and R. Iravani, "Potential-function based control of a microgrid in islanded and gridconnected modes”, IEEE Trans. Power Syst., vol. 25, no. 4, pp. 1883-1891, Nov. 2010.

[2] N. Jenkins N, “Embedded Generation”, in Power Engineering Journal, vol.9, pp.145-150, 1995.

[3] A. Sachit Gopalan, Victor Sreeram and H.C. Herbert Iu, "A review of coordination strategies and protection schemes for microgrids”, in Renew Sustain Energy Rev., vol.32, pp. 222-228, 2014.

[4] A. Oudalov and A. Fidgatti, "Adaptive network protection in microgrids", in International Journal of Distributed Energy Resources, vol.5, no.3, pp201-226, 2009.

[5] O. V. Gnana Swathika; S. Hemamalini, "Prims Aided Dijkstra Algorithm for Adaptive Protection in Microgrids," in IEEE Journal of Emerging and Selected Topics in Power Electronics, vol.PP, no.99, pp.1-1, 2016.

[6] M. H. Cintuglu; T. Ma; O. Mohammed, "Protection of Autonomous Microgrids using Agent-Based Distributed Communication," in IEEE Transactions on Power Delivery, vol.PP, no.99, pp.1-1, 2016.

[7] N. El Halabi a, M. García-Gracia a , J. Borroy a, J.L. Villa, "Current phase comparison pilot scheme for distributed generation networks protection”, in Applied Energy, vol. 88 pp. 4563-4569, 2011.

[8] Ustun, T.S.; Ozansoy, C.; Zayegh, A., "Modeling of a Centralized Microgrid Protection System and Distributed Energy Resources According to IEC 61850-7-420," IEEE Transactions on Power Systems, vol.27, no.3, pp.1560,1567, Aug. 2012.

[9] Taha Selim Ustun, Cagil Ozansoy and Aladin Zayegh, "Fault current coefficient and time delay assignment for microgrid protection system with central protection unit", in IEEE Transactions on power systems, vol. 28, no. 2, pp. 598-606, 2013.

[10]T. S. Ustun and R. H. Khan, "Multiterminal Hybrid Protection of Microgrids Over Wireless Communications Network," in IEEE Transactions on Smart Grid, vol. 6, no. 5, pp. 2493-2500, Sept. 2015.

[11]Laaksonen, H.J., "Protection Principles for Future Microgrids", in IEEE Trans. Power Electronics, vol.25, no.12, pp.2910,2918, Dec. 2010.

[12]Najy, W.K.A; Zeineldin, H.H.; Woon, W.L., "Optimal Protection Coordination for Microgrids With Grid Connected and Islanded Capability,", in IEEE Trans, Industrial Electronics , vol.60, no.4, pp.1668,1677, April 2013

[13]Laaksonen, H.; Ishchenko, D.; Oudalov, A, "Adaptive Protection and Microgrid Control Design for Hailuoto Island,", in IEEE Trans. On Smart Grid, vol.5, no.3, pp.1486,1493, May 2014 
[14]Y, Han, X Hu, D Zang, “ Study of Adaptive Fault Current Algorithm for Migrogrid Dominated by Inverter based Distributed Generators," in 2nd IEEE International Symposium on Power Electronics for Distributed Generation Systems, PEDG, pp. 852-854, 2010.

[15]R.M. Tumilty, M. Brucolit, G.M. Burt and T.C. Greent , "Approaches to Network Protection for Inverter Dominated Electrical Distribution Systems', in the 3rd IET International conference on Power Electronics, Machines and Drives, pp. 622-626, 2006.

[16]Aushiq Ali Memon, , Kimmo Kauhaniemi, "A critical review of AC Microgrid protection issues and available solutions", in Electric power systems Research, Volume 129, December 2015, Pages 23-31.

[17]K. O. Oureilidis and C. S. Demoulias, "A Fault Clearing Method in Converter-Dominated Microgrids With Conventional Protection Means," in IEEE Transactions on Power Electronics, vol. 31, no. 6, pp. 4628-4640, June 2016.

[18]T. Loix, T. Wijnhoven, and G. Deconinck, "Protection of microgrids with a high penetration of inverter-coupled energy sources," in Proc.CIGRE/IEEE PES Joint Symp. Integr.Wide-Scale Renewable Resources Power Del. Syst., 2009, pp. 1-6.

[19]E. Sortomme, S. S. Venkata, and J. Mitra, "Microgrid protection using communication-assisted digital relays,"in IEEE Trans. Power Del., vol. 25, no. 4, pp. 2789-2796, Oct. 2010.

[20]S. Mirsaeidi, D. M. Said, M. W. Mustafa, M. H. Habibuddin, and Kimia Ghaffari, "An analytical literature review of the available techniques for the protection of micro-grids," in Int. J. Elect. Power Energy Syst., vol. 58, pp. 300-306, Jun. 2014.

[21]R. Akella, H. Tang, and M.M. Bruce, "Analysis of Information Flow Security in Cyber-Physical System", in International Journal of Critical Infrastructure Protection, Vol. 3, pp:157-173, 2010.

[22]J. Hoyos, M. Dehus, and T. X. Brown, "Exploiting the goose protocol: A practical attack on cyberinfrastructure," in Globecom Workshops (GC Wkshps), 2012 IEEE, pp. 1508-1513.

[23]M. H. Cintuglu; T. Youssef; O. A. Mohammed, "Development and Application of a Real-Time Testbed for Multiagent System Interoperability: A Case Study on Hierarchical Microgrid Control," in IEEE Transactions on Smart Grid, vol.PP, no.99, pp.1-1, 2016.

[24]A. Cuzzocrea, C. Kittl, D. E. Simos, E. Weippl, and L. Xu, “Availability, Reliability, and Security in Informaiton Systems and HCI": IFIP WG 8.4, 8.9, TC 5 Internaitonal Cross-Domain Conference, CDARES 2013, Rgensbrg, Germany, September 2-6, 2013, Proceedings.

[25]Tarek A. Youssef, Mohamad El Hariri, Nicole Bugay and O. A. Mohammed, "IEC 61850: Technology Standards and Cyber-Security Threats," in the 16th IEEE International Conference on Environment and Electrical Engineering (EEEIC), Florence, Italy, 7-10 June, 2016.

[26]Mohamad El Hariri, Tarek A. Youssef, Abla Hariri and O. A. Mohammed, "Microgrids on Wheels: Not to Leave Security Behind," in IEEE Electrification e-Newsletter, June 2016.

[27]M. Ortuzar, J. Moreno, and J. Dixon, "Ultracapacitor-Based Auxiliary Energy System for an Electric Vehicle: Implementation and Evaluation," in IEEE Trans on Industrial Electronics, vol. 54, no. 4, pp. 2147-2156, Aug. 2007.

[28]Lijun Gao, R.A. Dougal, Shengyi Liu, "Power enhancement of an actively controlled battery/ultracapacitor hybrid,", in IEEE Transactions on Power Electronics, vol.20, no.1, pp.236-243, Jan. 2005.

[29]D. Shin, Y. Kim, J. Seo, N. Chang, Y. Wang, M. Pedram, , "Batterysupercapacitor hybrid system for high-rate pulsed load applications," in Design, Automation \& Test in Europe Conference \& Exhibition (DATE), 2011 , vol., no., pp.1,4, 14-18 March 2011. 
[30]P. Bajpai and V. Dash, "Hybrid renewable energy systems for power generation in stand-alone applications: A review," in Renewable and Sustainable Energy Reviews, vol. 16, no. 5, pp. 2926-2939, Jun. 2012.

[31]M. Farhadi and O. Mohammed, "Energy Storage Technologies for High-Power Applications," in IEEE Transactions on Industry Applications, vol. 52, no. 3, pp. 1953-1961, May-June 2016.

[32]A. Mohamed, V. Salehi, O. Mohammed, "Real-Time Energy Management Algorithm for Mitigation of Pulse Loads in Hybrid Microgrids,", IEEE Transactions on Smart Grid, vol.3, no.4, pp.1911,1922, Dec. 2012.

[33]M. Farhadi and O. A. Mohammed, "Performance Enhancement of Actively Controlled Hybrid DC Microgrid Incorporating Pulsed Load," in IEEE Transactions on Industry Applications, vol. 51, no. 5, pp. 3570-3578, Sept.-Oct. 2015.

[34]J.M. Sudhoff, S.D., "Reducing Impact of Pulsed Power Loads on Microgrid Power Systems,", IEEE Transactions on Smart Grid, vol.1, no.3, pp.270-277, Dec. 2010.

[35]R.A.Dougal, Shengyi Liu, R.E. White, "Power and life extension of battery-ultracapacitor hybrids,", IEEE Transactions on Components and Packaging Technologies, vol.25, no.1, pp.120,131, Mar 2002.

[36]T. Ma, M. H. Cintuglu and O. Mohammed, "Control of hybrid AC/DC microgrid involving energy storage, renewable energy and pulsed loads," in Industry Applications Society Annual Meeting, 2015 IEEE, Addison, TX, 2015, pp. 1-8.

[37]T. A. Youssef and O. Mohammed, "Adaptive SRF-PLL with reconfigurable controller for Microgrid in grid-connected and stand-alone modes," in IEEE Power \& Energy Society General Meeting, Vancouver, BC, 2013, pp. 1-5.

[38]Z. Jin, G. Sulligoi, R. Cuzner, L. Meng, J. C. Vasquez and J. M. Guerrero, "Next-Generation Shipboard DC Power System: Introduction Smart Grid and dc Microgrid Technologies into Maritime Electrical Netowrks," in IEEE Electrification Magazine, vol. 4, no. 2, pp. 45-57, June 2016.

[39]A. Mohamed, V. Salehi and O. Mohammed, "Real-Time Energy Management Algorithm for Mitigation of Pulse Loads in Hybrid Microgrids," in IEEE Transactions on Smart Grid, vol. 3, no. 4, pp. 1911-1922, Dec. 2012.

[40]Mustafa Farhadi, and Osama A. Mohammed, "Adaptive Energy Mangement in Redundant Hybrid DC Microgrid for Pulse Load Mitigation," in IEEE Transactions on Smart Grid, Vol. 6, no.1, pp.54-62, Jan. 2015.

[41] Maxwell, 16V small cell module, Model: BMOD0058 E016 B02 (16.2V-58 F), San Diego, CA. Online at: http://www.maxwell.com/images/documents/datasheet_16v_small_cell_module.pdf. 